\title{
Are transcendental theories of justice redundant?
}

Forthcoming in a booksymposium in The Journal of Economic Methodology, with a reply by Amartya Sen.

Ingrid Robeyns* (robeyns < at> fwb.eur.nl)

Final pre-publication version 8 November 2010

Amartya Sen's The Idea of Justice is a very rich book, with many aspects worth discussing. I will limit myself here to one major claim that Sen makes, namely that transcendental theories of justice are redundant. I will argue that this 'Redundancy Claim' is mistaken, since for justiceenhancing actions we need both transcendental and non-transcendental theorising of justice. Nevertheless I endorse an implication of the Redundancy Claim, namely that theorists of justice should shift their focus from transcendental theorizing towards thinking about justiceenhancing change, thereby restoring the balance between transcendental and non-transcendental theorizing. I will argue that this 'Rebalancing Claim' not only follows from the (mistaken) Redundancy Claim, but also from another argument which Sen advances about the current practice of philosophers of justice. I will conclude that the Redundancy Claim has to be rejected, but that this is not a big loss, since what is really important is the Rebalancing Claim, which is vindicated.

\section{Transcendental theories and the Redundancy Claim}

How does Sen understand transcendental theories of justice? Transcendental theories of justice are theories that describe a perfectly just situation: no further justice-improvements are possible. Transcendental theory

"concentrates its attention on what it identifies as perfect justice, rather than on relative comparisons of justice and injustice. It tries only to identify social characteristics that cannot be transcended in terms of justice, and its focus is thus not on comparing feasible societies, all of which may fall short of the ideals of perfection. The inquiry is aimed at identifying the nature of 'the just', rather than finding some criteria for an alternative being 'less unjust' than another." (p. $5-6)$.

Sen argues that transcendental theories are redundant if our aim is to actually make choices that advance justice: "If a theory of justice is to guide reasoned choice of policies, strategies or institutions, then the identification of fully just social arrangements is neither necessary nor sufficient" (p. 15). Call this the Redundancy Claim. I agree with one part of the Redundancy Claim, namely that transcendental theory is not sufficient for guidance, and will therefore only 
focus on the claim that it is not necessary. This latter part of the Redundancy Claim I believe to be mistaken.

Sen argues that a number of basic injustices don't need transcendental theory in order for us to understand and agree that they concern gross injustices (xi-xii). Indeed, all theories of justice would agree that corruption in politics, power abuse by economic actors, or the training of child soldiers are blatant cases of injustice, and that we don't need a transcendental theory of justice to spell that out. Yet we cannot extrapolate from this particular subset of injustices (i.e. manifest and clearly remediable cases of injustice) to the entire set of injustices. My belief is that the usefulness of transcendental theory is limited and currently enjoys a too high status among academic philosophers, but that we are mistaken if we believe that we can entirely do without.

\section{Two arguments against the Redundancy Claim}

I will offer two arguments against the Redundancy Claim. The first argument is that many cases of injustice are complex and often subtle, and therefore more difficult to identify and analyse as cases of injustice than cases of basic injustice. Take the case of gender justice in liberal societies, which have seen many decades of feminist activism, and where most citizens explicitly support equal rights for men and women. In those societies, many citizens believe that gender justice is fully realised. But how do we judge a claim of full or perfect justice? If we want to analyse a claim of perfect gender justice, we need transcendental principles of justice.

We need to specify which conditions have to be met before we consider a certain state of affairs as perfectly just. In order to assess such a claim of gender justice, one needs principles that tell us when a society is gender just. These principles are transcendental principles of justice (even though they are only transcendental in one domain, namely gender relations). Often the most effective way to argue for a claim of an injustice that is not blatant, is by arguing for ideals of justice, that is, arguing for principles of transcendental justice (in general, or in a particular domain), and empirically showing that these principles are not met. Again, social activists make ample use of such transcendental principles of justice and of this kind of public reasoning, for example when they invoke an ideal of substantive equality of opportunity. Summing up, judgments about the comparison of complex cases of injustice implicitly or explicitly do refer to ideals of justice. Not just in academic work, but also in real-life public discussions.

The second argument for the non-redundancy of transcendental theories stems from the nature of the non-transcendental theorising of justice, which is the theorising that guides our justice-enhancing actions and policies. Non-transcendental theorising of justice entails but is not limited to the comparative approach to justice, the approach that Sen champions in The Idea of Justice. For example, non-transcendental theorising of justice also includes theorising on 
how to weigh different principles of justice, or theorising on what to do if in the long run we can achieve a more just state, but whereby this requires sacrificing one generation for the sake of the following generations.

I believe that non-transcendental theories of justice require transcendental theories. Non- transcendental theories of justice give us a chain of changes that are needed in order to reach the most just social state among all feasible social states. We need to have a complete 'navigation map', a clear vision of how to go from where we are to where we want to be. We need an entire path of justice-enhancing actions, not only a comparison between two states which comparative justice offers us. If we limit ourselves to the comparative approach, we may choose for an injustice-reducing action that may benefit us in the short run, but may lead us to a suboptimal situation (from the point of view of justice) in the long run, due to the pathdependency of our actions.

Suppose that we can represent the degree of justice of a certain situation with a number, on a scale where 100 represents the fully just social state. The initial social state A has a justicevalue of 50. From A we can move to either B or S, with B corresponding to a justice value of 70 and $\mathrm{S}$ of 55 . If we are in A, and only compare B and S, then the conclusion is easy: we have to take action so that we end up in social state B. But our possibilities for further action are not independent of this first choice. Suppose that in the best-case scenario we can move from B to $\mathrm{C}$, with $\mathrm{C}$ having a justice value of 80 . From $\mathrm{S}$, however, we will be able to move to $\mathrm{T}$ where we can realize a justice value of 95 . We cannot move from B to $\mathrm{T}$. It then becomes clear that in order to make a reasoned decision between B and S, we need to know the 'paths of change' that $\mathrm{B}$ and $\mathrm{S}$ are on, and those paths are directing us towards an ideal, that is, a transcendental theory. Clearly the comparative approach is an important element of this more complete story of how to decide what to do - but that complete story also needs a vision of the ultimate goal, that is, a transcendental theory of justice. Thus, I conclude that transcendental theory is in nonbasic cases necessary for justice-enhancing change, and that therefore the Redundancy Claim is mistaken.

Note that my arguments against the general validity of the Redundancy Claim do not require that there is an agreement on the transcendental principles of justice, or that these principles are completely spelled out in each and every detail. If there is no agreement, then each disagreeing party will need its own transcendental principles in order to make up their own minds about which injustice-reducing actions to defend. Similarly, completeness is not required for transcendental theories to be useful; in fact, many transcendental principles of justice are plural and often somewhat vague and thus require further interpretation before they can be put into practice. But even if a transcendental account of justice is incomplete, or even if it consists of a plurality of principles which need to be weighted by public reasoning or by intuition, it 
does give us a set of standards or ideals against which to judge different possible paths of social change. The 'navigation maps' which we require to guide reasoned choice of policies, strategies and institutions for questions of non-blatant injustices must include a specification of our ultimate goal, that is, transcendental principles of justice.

\section{Vindicating the Rebalancing Claim}

So far I have advanced two arguments for why I believe that the Redundancy Claim is not correct. Yet suppose the redundancy claim were correct: what would have been its implications? A weak implication would be that theorists of justice devote too much attention and energy to transcendental theory, since it is neither necessary nor sufficient for our ultimate goal, which is to reduce injustices. Still, transcendental theory would play some other useful role, and we therefore shouldn't abolish it entirely. Rather, we should restore the balance between the attention we devote to transcendental theory and non-transcendental theory. A stronger implication would be that theorists of justice should stop conducting all transcendental theorising, since it does not contribute anything towards that goal or any other valuable goal. I don't think Sen would endorse the strong implication, given how important he judges John Rawls's theory of justice to be, which Sen believes to be a transcendental theory. I read Sen's work, both in The Idea of Justice and other work, as supporting the weak implication.

Sen's concern is that theories of justice should ultimately be 'practical'. Sen describes the aim of the theory of justice as "to clarify how we can proceed to address questions of enhancing justice and removing injustice, rather than to offer resolutions of questions about the nature of perfect injustice" (p. ix). Not all philosophers espouse this view: some believe that the proper role of political philosophy is not to answer the question what to do, but rather to seek the truth, whether or not the truth makes any difference to what we should do.

Of course, the truth-seeking and the practical need not be mutually exclusive. Indeed, the practical approach to justice needs to be based on true knowledge about the world and about justice, since otherwise the guidance that the philosopher harvests from her reasoning may be misleading. Yet we don't necessarily need to know the full truth, and all possible details of the truth: at some point the added value to practice of further truth-seeking knowledge becomes infinitesimally small, and may therefore not be the best use of our scarce time.

There is a growing feeling among some political philosophers that we have reached that point, and that the status incentives in (Anglo-American) academic philosophy departments are biased in favour of those seeking further details regarding the truth of justice, even if the added practical value has become tiny, and despite the fact that enormous amounts of work need to be done in non-transcendental theory. If we really care about justice, and not merely enjoy the intellectual stimulation that political philosophy offers, we should be doing something about it, 
for example by collaborating with policy scholars in figuring out how to design philosophically-sound justice-enhancing policies, or collaborating with critical citizens or social activists in thinking about how to effectively analyse cases of gross injustice, including those that are caused by the state. Yet that kind of 'applied' or 'interdisciplinary' work, which is often muddy and not elegant at all, doesn't enjoy high status in Anglo-American political philosophy. Are we having our priorities right?

Sen argues in The Idea of Justice that mainstream theorists of justice have their priorities wrong: "Importance must be attached to the starting point, in particular the selection of some question to be answered (for example, 'how would justice be advanced?'), rather than others (for example, 'what would be perfectly just institutions?'). [...] Given the present balance of emphases in contemporary political philosophy, this will require a radical change in the formulation of the theory of justice" (9). Let me call the argument that we need to shift the nature of contemporary theorizing about justice away from the transcendental truth-seeking, towards the practical, and thereby also rearrange and rebalance the status that we allocate to different types of philosophical enquiry, the Rebalancing Claim.

The Rebalancing Claim is a weak implication of the Redundancy Claim, and this may perhaps explain Sen's insistence on the Redundancy Claim. Yet the Rebalancing Claim also follows from Sen's general argument about the present dominant practice of contemporary theories of justice. In fact, I believe that many philosophers working on specific cases of injustice, such as global justice, gender justice, or environmental justice, reject the Redundancy Claim but endorse the Rebalancing Claim. That particular position acknowledges that transcendental theory does have a role to play, but that it currently enjoys too much status and receives too much attention in academia, and that therefore its role should be much more limited than is currently the case. If the Redundancy Claim is mistaken but the Rebalancing Claim can be convincingly argued for, then I believe that nothing important is lost, and that the claim that is really important is vindicated.

Yet while I agree with the Rebalancing Claim, I do have one qualification to add. In one respect I think Sen is too pessimistic in his characterisation of contemporary theorising about justice, since much of the kind of work that he is advocating is already being conducted. For example, there is a huge literature on particular aspects of global injustices, ranging from Iris Marion Young's analysis of individual and collective responsibilities for the employment conditions of workers in sweatshops, to Leif Weinar's analysis of why the sale of oil by dictators in oil-rich African countries to oil companies in Europe and the US is a severe property rights violation of the afflicted African populations. ${ }^{1}$ These are examples of excellent pieces of theorizing about concrete cases of injustice. If one looks carefully, and not only in the most prestigious journals, there is a huge literature out there that does analyse such cases of 
injustices, though it may not always attract the spotlights to the same degree as the universal theories of Rawls, Nozick, Dworkin, and others. In my reading of the contemporary literature on justice and injustices, the problem is not so much that this kind of research is not taking place, but rather that among too many philosophers it doesn't enjoy high status and is not considered 'theorising about justice' but rather classified as applied ethics or case studies on injustices. Such attitude underestimates the importance of this type of analysis. Thus, my assessment of the situation differs from Sen's assessment in so far as I think that the kind of work he is advocating does happen; I rather think the problem lies in the limited status and the non-canonical position of this work compared to more abstract, universal, general theorising about justice.

I am grateful to Martijn Boot, Pablo Gilabert, Anca Gheaus, Anders Schinkel and commentators at Crooked Timber for very helpful comments and illuminating discussions, and to the Netherlands Organisation for Scientific Research (NWO) for research funding.

${ }^{1}$ Iris Marion Young (2004) 'Responsibility and global labour justice', Journal of Political Philosophy, 12(4), pp. 365-388; Leif Weinar (2008) 'Property Rights and the Resource Curse', Philosophy and Public affairs, 36(1), pp. 2-32. 